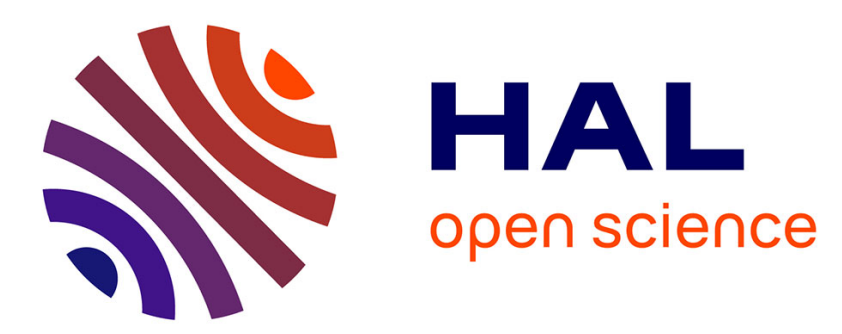

\title{
A first approach on the failure mechanisms of IGBT inverters for aeronautical applications: effect of humidity-pressure combination
}

Hassan Abbad, Stephane Azzopardi, Eric Woirgard, Jean-Yves Delétage, P. Rollin, Karl Marchand, Tony Lhommeau, Michel Piton

\section{To cite this version:}

Hassan Abbad, Stephane Azzopardi, Eric Woirgard, Jean-Yves Delétage, P. Rollin, et al.. A first approach on the failure mechanisms of IGBT inverters for aeronautical applications: effect of humiditypressure combination. IEEE International Power Electronics Conference, Jun 2010, Sapporo, Japan. pp.xx-xx. hal-00584142

\section{HAL Id: hal-00584142 \\ https://hal.science/hal-00584142}

Submitted on 7 Apr 2011

HAL is a multi-disciplinary open access archive for the deposit and dissemination of scientific research documents, whether they are published or not. The documents may come from teaching and research institutions in France or abroad, or from public or private research centers.
L'archive ouverte pluridisciplinaire HAL, est destinée au dépôt et à la diffusion de documents scientifiques de niveau recherche, publiés ou non, émanant des établissements d'enseignement et de recherche français ou étrangers, des laboratoires publics ou privés. 


\title{
A first approach on the failure mechanisms of IGBT inverters for aeronautical applications: effect of humidity-pressure combination
}

\author{
H. Abbad*, S. Azzopardi*, E. Woirgard*, J-Y. Deletage*, \\ P. Rollin**, K. Marchand***, T. Lhommeau****, M. Piton***** \\ * Laboratoire IMS, Université de Bordeaux, 351 cours de la Libération - 33405 Talence Cedex, France \\ ** Technofan, 10 place Marcel Dassault, ZAC du Grand Noble, BP 30053, 31702 Blagnac, France \\ *** Epsilon Ingénierie, 10 rue Jean Bart, BP 97431, 31674 Labège Cedex, France \\ **** Hispano-Suiza. RP René Ravaux site de Villaroche-Réau, 77550 Réau, France
}

\begin{abstract}
Comparing to the most common reliability tests this work presents a new approach of accelerated testing, by combining temperature, humidity and pressure cycling with voltage stress. A design of experiments methodology has been proposed to test IGBT inverters and understand environmental factors effect. The humidity-pressure combination effect is studied for various IGBT inverter packaging materials.
\end{abstract}

Index terms-Reliability, failure mechanisms, IGBT, design of experiments. multiphysics simulation.

\section{INTRODUCTION}

Aeronautical environment is particularly severe for electronic components (IGBT, capacitors, solder joints, etc). Their reliability is highly affected by temperature, humidity, vibration and pressure. It is important to estimate power electronics systems reliability by taking into account their environment.

More electric architecture aims at reducing weight, fuel consumption and operational cost by replacing conventional energy (mechanics, hydraulics and pneumatics) by electrical energy. Power electronics systems are more and more used in aircrafts. Consequently, it is essential to study their reliability in harsh environment related to aeronautics applications.

In this study, we focus only on the humiditypressure combination effects for various IGBT inverter packaging materials.

\section{MethodologicAl APPROACH}

\section{A. Selected equipments}

Two different inverters technologies are tested: an inverter designed on an Insulated Metalized Substrate (IMS), localized in pressurized environment (Fig. 1) and an IGBT module (Fig. 2) localized in nonpressurized environment with high and low temperatures, humidity, pressure and vibration. These components, using hybrid technology, are made of a multi-layer structure: various materials are soldered together.

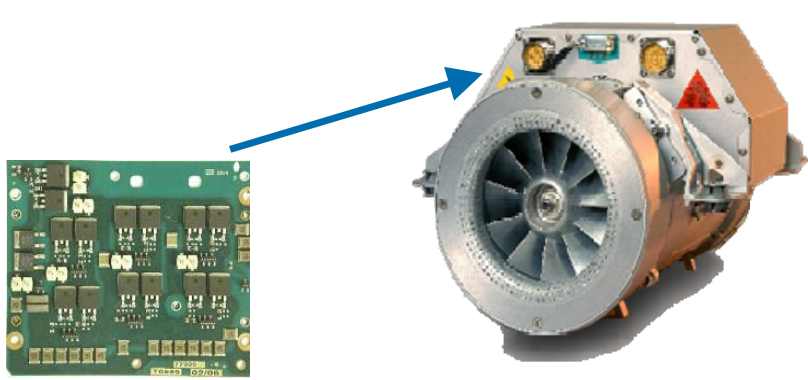

Fig. 1. IGBT Inverter on Metalized Substrate localized in the ventilation control system

The IGBT module is prone to harsh environmental conditions; high temperature cycles, humidity and pressure cycles.

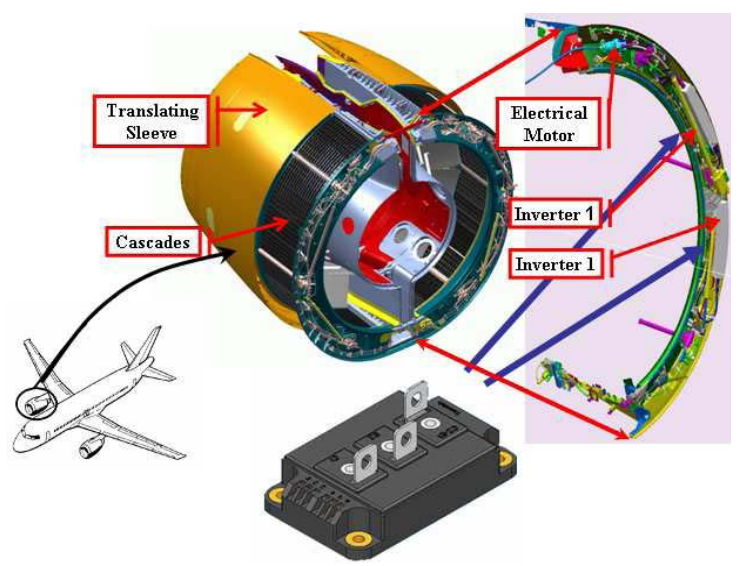

Fig. 2 IGBT Module localized in the motor Insulated nacelle in a non hermetic box

A previous work [1] has shown that thermal fatigue leading to thermo-mechanical stress induces solder joint delamination between the substrate and baseplate (Fig. 3). Resulting from the thermal cycling process, it has been observed that after 2000 cycles, the baseplate solder presents a delamination along the substrate periphery, where the thermo-mechanical constraints are 
predominantly localized. The delamination progress towards the solder center is observed (Fig. 3-b).

This phenomenon consists in the solder cracking between the metalized substrate and the baseplate due to the mismatch of the coefficient thermal expansion between materials.

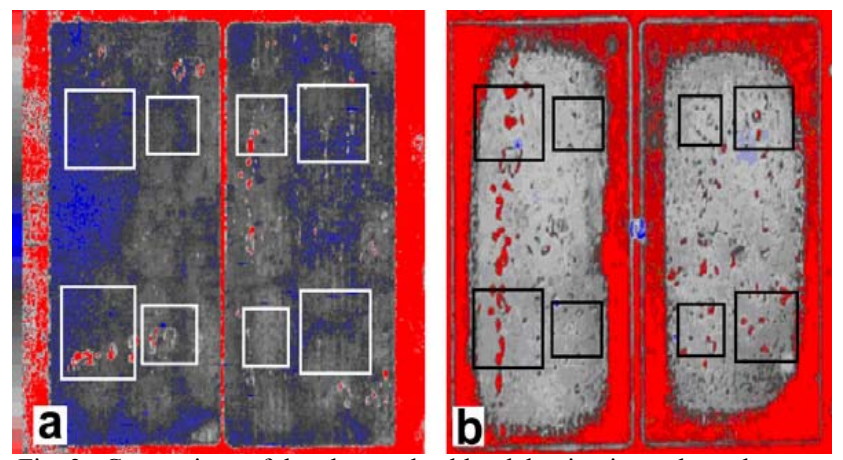

Fig. 3. Comparison of the observed solder delamination at baseplate level between non-aged IGBT (a) and after 2000 thermal cycles (b), the dice positions are highlighted

As a consequence this will induce an increase in the package thermal resistance, eventually inducing a chip failure (device burn-out).

\section{B. Methodological Approach}

This work points out the time to failure of these technologies according to their electrical and environmental mission profile. The first step is to study the effect of the humidity-pressure combination on the various materials of the packaging, and secondly to combine humidity, pressure, temperature stresses with the electrical operating of the IGBT inverter on IMS substrate

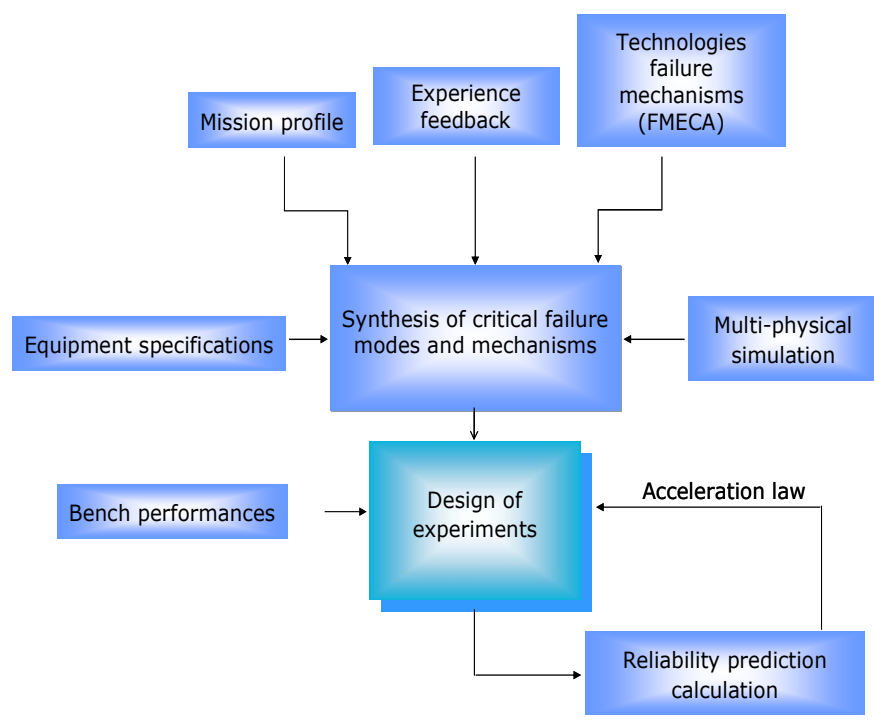

Fig. 4. Methodological approach

The methodological approach is based on the identification of critical failure mechanisms and failure criteria by analyzing technologies and exploiting experiments feedback. Accelerated tests results adjust the acceleration laws for a better reliability prediction (Fig. 4).

\section{RELIABILITY PREDICTION}

\section{A. Failure mechanisms and failure criteria}

This environmental cycling combined to an electrical stress is a new tool to determine the failure mechanism and their criteria. The control parameters should be carefully selected. Many studies ([2], [3], [4], [5]) have demonstrated that parameters like the junction temperature $\left(T_{j}\right)$, thermal resistance $\left(R_{t h}\right)$ and emitter to collector saturation voltage $\left(\mathrm{V}_{\text {cesat }}\right)$ have to be monitored. The increase of $\mathrm{R}_{\text {th }}$ by $20 \%$ and $\mathrm{V}_{\text {cesat }}$ by $5 \%$ is considered as a specification limit. As shown in [5], the I-V characteristics of IGBT decrease with ageing as shown in the Fig. 5.

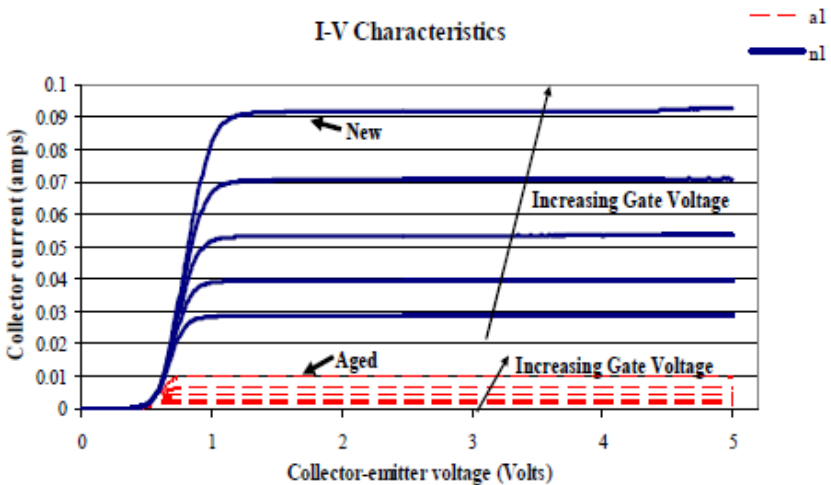

Fig. 5. I-V curves for aged and new IGBTs under low gate voltages

\section{B. Existing accelerated tests}

Comparing to the most common accelerated tests as Temperature Cycling (TC), High-Temperature Operating Life (HTOL), Temperature-Humidity-Bias (THB) and Vibration, the main purpose of this projet aims at presenting a new approach of accelerated testing, by combining temperature cycling, humidity cycling, pressure cycling and voltage stress.

The concept of accelerated testing is to compress time and accelerate the failure mechanisms in a reasonable test period so that product reliability can be assessed. The only way to accelerate time is to stress potential failure modes. Accelerated life tests are also used extensively to help making predictions.

In the literature [6], no combined temperature, humidity, pressure and electrical accelerated factors has been done in the area of accelerated testing.

We present hereafter an overview of accelerated testing using the studied environmental factors, with the potential failure mechanisms and acceleration models found in the literature 
In HTOL, devices are subjected to elevated temperature under electrical bias for an extended period of time. The dominant thermally accelerated failure mechanisms will follow the classical Arrhenius relationship (1). It is not only used in reliability to model temperature-dependent failure-rate mechanisms, but it also expresses a number of different physical thermodynamic phenomena.

$A_{T}=\operatorname{Exp}\left\{\frac{E_{a}}{K_{B}}\left[\frac{1}{T_{U s e}}-\frac{1}{T_{\text {Stress }}}\right]\right\}$

$\operatorname{Ln}\left(t_{f}\right)=C+\frac{E_{a}}{K_{B} T}$

$A_{T}=$ temperature acceleration factor

$E_{a}=$ activation energy

$K_{B}=$ Boltzmann's constant

$T_{\text {Use }}=$ Use temperature $\left({ }^{\circ} \mathrm{K}\right)$

$T_{\text {Stress }}=$ test temperature $\left({ }^{\circ} \mathrm{K}\right)$

$t_{f}=$ time to failure

$C=$ constant

In THB acceleration model, test devices have to withstand elevated temperatures and humidity under electrical bias for an extended period of time. For example, the most common THB test is a 1000-hour test at $85^{\circ} \mathrm{C}$ and 85 percent relative humidity. This includes a relationship (2) between life-andtemperature (Arrhenius model) and life-and-humidity (Peck model).

$A_{T}=\operatorname{Exp}\left\{\frac{E_{a}}{K_{B}}\left[\frac{1}{T_{\text {Use }}}-\frac{1}{T_{\text {Stress }}}\right]\right\}$

$\operatorname{Ln}\left(t_{f}\right)=C+\frac{E_{a}}{K_{B} T}-m \operatorname{Ln}(R)$

$A_{H}=\left(\frac{R_{\text {Stress }}}{R_{\text {Use }}}\right)^{m}$

$A_{T H}=A_{T} A_{H}$

$A_{H}=$ Humidity acceleration factor

$A_{T H}=$ Temperature Humidity acceleration factor

$R_{\text {Use }}=$ use humidity $\left({ }^{\circ} \mathrm{K}\right)$

$R_{\text {Stress }}=$ test humidity $\left({ }^{\circ} \mathrm{K}\right)$

$m=$ humidity constant

In $\mathrm{TC}$, test devices have to withstand a number of cycles of alternate high and low extreme temperatures. This stress produced in temperature cycling is related to thermal expansion and contraction undergone in the material. The most widely used model in industry is the Coffin-Manson model (3).

$A_{T C}=\frac{N_{\text {use }}}{N_{\text {Stress }}}=\left[\frac{\Delta T_{\text {Stress }}}{\Delta T_{\text {Use }}}\right]^{k}$

$\operatorname{Ln}\left(t_{f}\right)=C-K \operatorname{Ln}(\Delta T)$

$A_{T C}=$ temperature cycle acceleration factor
$N_{\text {Stress }}=$ number of cycles tested

Nuse $=$ equivalent number of field cycles

$\Delta T_{\text {Stress }}=$ temperature cycle test range

$\Delta T_{U s e}=$ Nominal daily temperature change in the field

$K=$ temperature cycle exponent

In order to evaluate the acceleration factor combining the influence of temperature, humidity and pressure cycling, the parameter activation energy $E a$ may be obtained through experimentation.

\section{DESIGN OF EXPERIMENTS}

\section{A. Factors and levels}

Design of experiments methodology has been chosen to make these tests and to evaluate the evolution of electric, thermal and thermo-mechanical parameters. It concerns the collector to emitter saturation voltage $\left(\mathrm{V}_{\text {cesat }}\right)$, IGBT junction Temperature $\left(\mathrm{T}_{\mathrm{j}}\right)$, leakage current $\left(\mathrm{I}_{\mathrm{ces}}\right)$ and solders joints evolution.

$2^{\mathrm{k}-\mathrm{p}}$ design of experiment is used [7], where $k$ represents the number of factors and $p$ a constant parameter equal to 1 .

Four factors are combined: temperature, humidity, pressure and voltage.

The typical test cycle aims at reproducing environmental constraints resulting from mission profile and system specifications (Fig. 6).

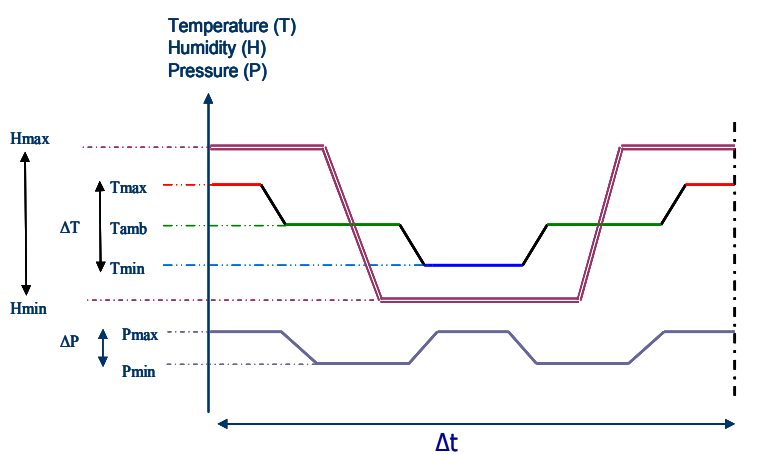

Fig. 6. Typical combined constraints test cycle

\section{B. Matrix of experiments}

The matrix of experiments contains eight experiments with two factor levels - and + as shown in Table I. The multi-constraints bench controls the four factors of the experiments: temperature $\Delta \mathrm{T}$, humidity $\Delta \mathrm{H}$, pressure $\Delta \mathrm{P}$ and voltage supply $\mathrm{U}$.

These experiments consist in varying simultaneously the amplitude of the three environmental constraints and the voltage stress. 
TABLE 1

Matrix of experiments

\begin{tabular}{|c|c|c|c|c|}
\hline \multirow{2}{*}{ Experiment } & \multicolumn{5}{|c|}{ Controlled factors } \\
\cline { 2 - 5 } & $\Delta \mathbf{T}\left({ }^{\circ} \mathbf{C}\right)$ & $\Delta \mathbf{H}(\%)$ & $\Delta \mathbf{P}(\mathbf{m b a r})$ & $\mathbf{U}(\mathbf{V})$ \\
\hline 1 & - & - & - & - \\
\hline 2 & + & - & - & + \\
\hline 3 & - & + & - & + \\
\hline 4 & + & + & - & - \\
\hline 5 & - & - & + & + \\
\hline 6 & + & - & + & - \\
\hline 7 & - & + & + & - \\
\hline 8 & + & + & + & + \\
\hline
\end{tabular}

The chosen system response is the number of cycles leading to failure. The equation (4) highlights the effect of each factor and the effect of first order interactions.

$N f=a_{0}+\sum_{i=1}^{i=n} a_{i} \cdot X_{i}+\sum_{i=j=1}^{i=j=n} a_{i} \cdot a_{j} \cdot X_{i} \cdot X_{j}$

$a_{0}$ : System response mean (5).

$N_{f}$ : Number of cycles to failure.

$a_{i}, a$, : Factors effects (6).

$X_{i}$ : Controlled factors ( $\mathrm{T}, \mathrm{H}, \mathrm{P}$ and $\left.\mathrm{U}\right)$.

$a_{0}=\bar{Y}=\frac{1}{n} \sum_{i=1}^{n} Y_{i}$

$a_{j}=e_{a_{j}}=y_{x_{j}}{ }^{+}-a_{0}$

$y_{x_{j}}$ is the observed response at the $x_{j+}$ level of $x_{j}(7)$.

$n+$ is the number of experiments at the $x_{j+}$ level of $x_{j}$. $e_{a j}$ is the $a_{j}$ coefficient effect.

$y_{x_{j}}{ }^{+}=\frac{1}{n^{+}} \sum_{i=1}^{n^{+}} y_{i}^{+}$

\section{MULTIPHYSICS SIMULATION}

The purpose of multiphysics simulation is to confirm the experiments results by determining the system failure criteria. Fluidics, electro-thermal and humidity models are combined to estimate the time to failure of IGBT inverters. Modeling platform takes into account material characteristics, electrical and environmental mission profiles.

\section{A. Module description}

The IGBT module (fig 7) is compounded of the power ground encapsulated in a plastic shell included silicone gel performing the electrical insulation. (PBT means Polybutylene Terephtalate)

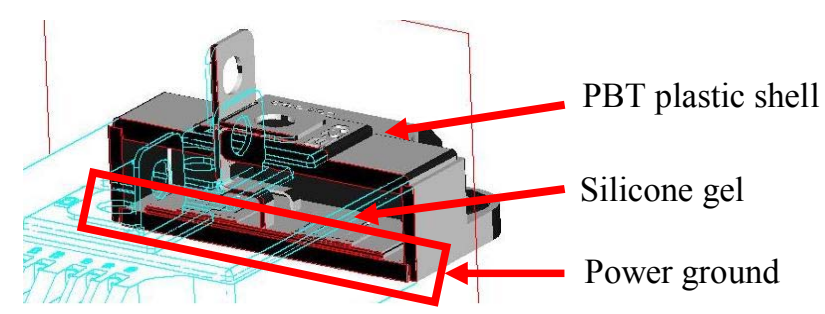

Fig. 7: IGBT module cross-section

The IGBT module is composed by 3 parts (fig 8 ):

- The active part (silicon die).

- The insulation part (Metallised substrate).

- The baseplate of the component.

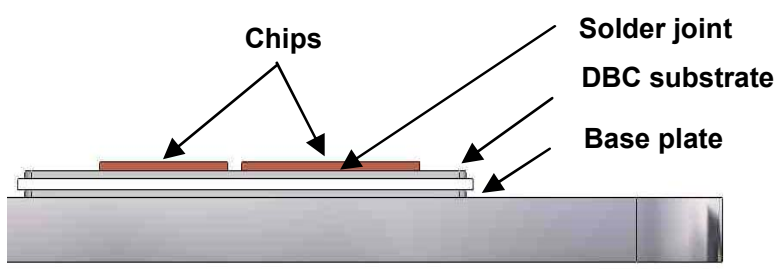

Fig. 8: IGBT module packaging

The IMS converter (fig 9) is composed of:

- The active part (IGBT D2pack).

- The insulation part (Insulated Metallised Substrate).

- The heatsink of the system

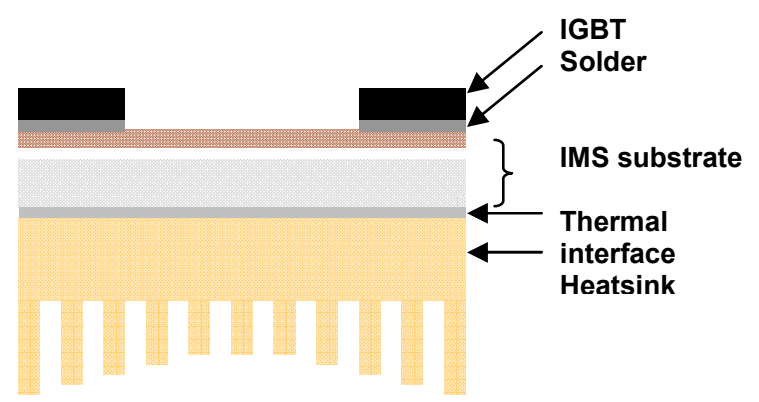

Fig. 9: IMS converter packaging

\section{B. Humidity Pressure test: results and discussion}

To understand the effect of the pressure on the diffusion of humidity, different samples of materials (Fig. 10) inside the IGBT module (PBT, Silicone) and the IMS converter (FR4, IMS, IGBT) were subjected to high relative humidity rate equal to $95 \%$ and temperature equal to $60^{\circ} \mathrm{C}$ (Fig. 11) in order to be close to saturation, and then a low value of pressure was 
applied, $150 \mathrm{mbar}$ with temperature equal to $20^{\circ} \mathrm{C}$ (Fig. 12).

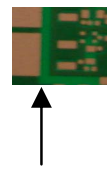

IMS

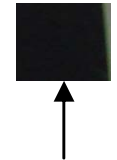

Silicone

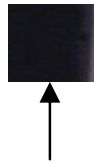

PBT

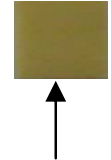

FR4

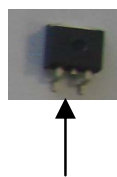

IGBT D2pack
Fig. 10. Various samples for humidity-pressure tests

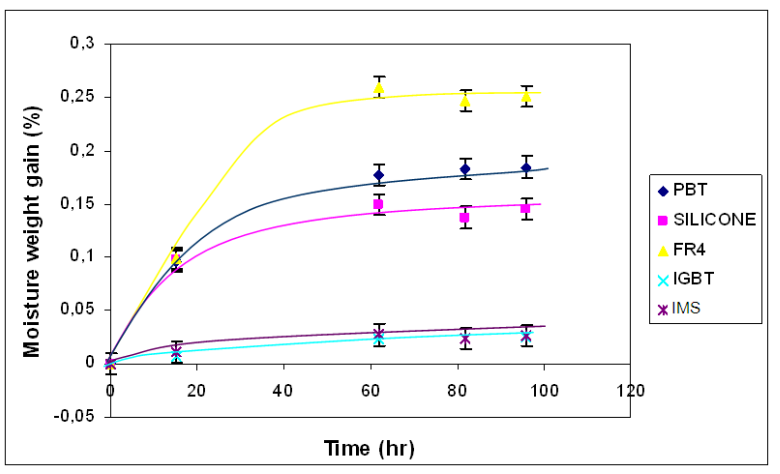

Fig. 11. Moisture weight gain for different polymers (experiment)

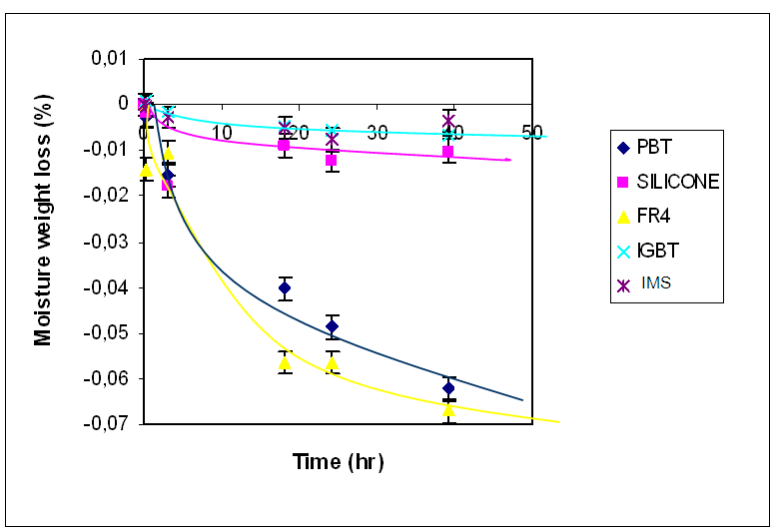

Fig. 12. Moisture weight loss for different polymers (experiment)

As shown in [8] and considering that a diffusion coefficient $D$ is constant, a diffusion coefficient $D$ can be determined from the experimental data by the following equations (8):

$\frac{M_{t}}{M_{\infty}}=1-\exp \left[-7.3\left(\frac{D . t}{h^{2}}\right)\right]^{k}$

where $M t$ is total mass of the diffusion substance absorbed by the sample at time $t$, and $M_{\infty}$ is the equilibrium mass of the absorbed substance, and $h$ is the thickness of the specimen.

Based on the experimental data, the moisture diffusion analysis of the different materials of the packaging was performed using a boundary element method. The diffusion phenomena can be described by the diffusion equation (9).

$$
\frac{\partial C}{\partial t}=D\left(\frac{\partial^{2} C}{\partial x^{2}}+\frac{\partial^{2} C}{\partial y^{2}}+\frac{\partial^{2} C}{\partial z^{2}}\right),
$$

where $C$ is the local moisture concentration, $D$ is the isotropic moisture diffusivity, and $t$ is time.

The mean humidity $W$ inside the volume of the sample is related to the mass of the absorbed water by the following relationship (10) :

$$
W(t)=\frac{C(t)}{C s a t}=\frac{m_{\text {water }}}{m_{\text {watersat }}}
$$

- $C(t)$ is the water mass concentration in the volume of the sample.

- Csat is the saturated value of $C$ variable in the sample

The simulation methodology consists in coupling a thermal simulator, a thermo-mechanical and an electrical one [9]. The results of this experimentation are implemented into the model via a hygro-thermal package. The humidity models based on Fick's laws use the boundary element method (BEM) via the hygro simulator. The 3-D humidity simulator is centered on the humidity $\mathrm{w}(\mathrm{x}, \mathrm{y}, \mathrm{z}, \mathrm{t})$ variable. It is an analogy with the thermal variable $\mathrm{T}(\mathrm{x}, \mathrm{y}, \mathrm{z}, \mathrm{t})$. Consequently, the thermal equations are used. By applying the heat equation (pseudo-fick diffusion) using the method of the separation of variables and a solution under trigonometric series formulation, we find in literature [10]:

$C(x, t)=C 1-\frac{C 1 \cdot x}{e}-\frac{2}{\pi} \sum_{n=1}^{\infty}\left[\frac{C 1}{n} \cdot \exp \left(-\frac{n^{2} \pi^{2} \cdot D}{e^{2}} \cdot t\right) \cdot \sin \left(\frac{n \cdot \pi}{e} \cdot x\right)\right]$

where $e$ is the thickness of the sample.

By definition :

$$
m_{\text {water }}(t)=\int_{\text {volume }} C(x, t)=L . l \cdot \int_{x=0}^{e} C(x, t)
$$

And in particular,

$$
m_{\text {water }}(t \rightarrow \infty)=L . l . \frac{C 1 . e}{2}
$$

After integration in the sample volume, we obtain the water mass:

$$
\frac{m_{\text {wate }}(t)}{m_{\text {wate }}(t \rightarrow \infty)}=1-\frac{8}{\pi} \sum_{n=0}^{\infty}\left[\frac{1}{(2 n+1)^{2}} \cdot \exp \left(\frac{(2 n+1)^{2} \pi^{2} D}{e^{2}} \cdot t\right)\right]
$$


Using the equation (14), we intend to use an extraction method of $D$ from the experimental data. In fact, around $\mathrm{t}=0$, we can simplify this equality:

$$
D=\pi \cdot\left(\frac{\alpha \cdot e}{4}\right)^{2}
$$

$\alpha$ represents the gradient at $(t \rightarrow 0)$ of the of figure 11 illustrating the water mass evolution.

The extraction of de Csat is done by matching the equations (10) and (11) when $\mathrm{t} \rightarrow \infty$ :

$$
C_{\text {sat }}=\frac{2 . m_{\text {water }}(t \rightarrow \infty)}{\text { RH. } V_{\text {sample }}}
$$

where $R H$ is the relative humidity and $V$ the volume of the sample.

The calculated values of the saturation concentration and the moisture diffusivity are presented in table II. These data are implemented in the humidity model.

TABLE II

Moisture diffusivity and concentration

\begin{tabular}{|l|c|c|c|c|}
\cline { 2 - 5 } Material & FR4 & PBT & Silicone & IMS \\
\hline $\mathbf{D}\left(\mathbf{m}^{2} / \mathbf{s}\right)$ & $4.46 .10^{-13}$ & $9.74 .10^{-12}$ & $1.71 .10^{-11}$ & $1.96 .10^{-12}$ \\
\hline Csat $\left.\mathbf{( k g} / \mathbf{m}^{\mathbf{3}}\right)$ & 28.4 & 9.4 & 6.3 & 2.1 \\
\hline
\end{tabular}

Each sample is represented by a rectangular parallelepiped (Fig. 13), whose the faces are subjected to the boundary conditions of relative humidity.

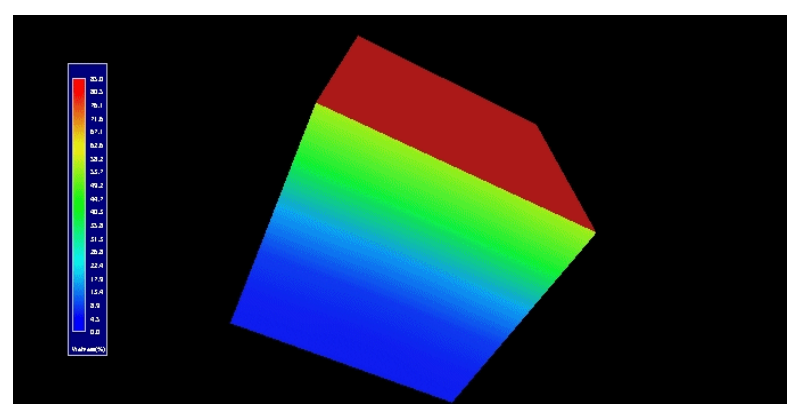

Fig.13: Humidity diffusion mapping observed after simulation

The following graphs sum up the comparison between the humidity models and experimental data for two examples of samples, PBT and IMS. They represent the mean humidity $W$ inside the volume of the sample as a function of time.

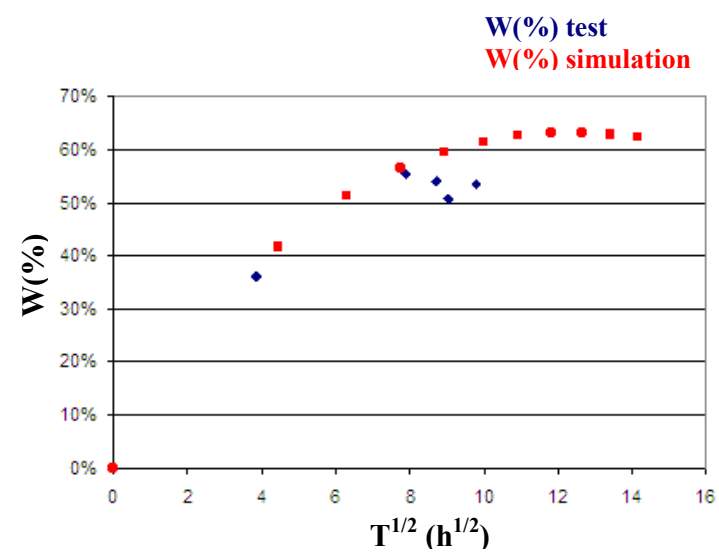

Fig. 14. Mean humidity for PBT sample

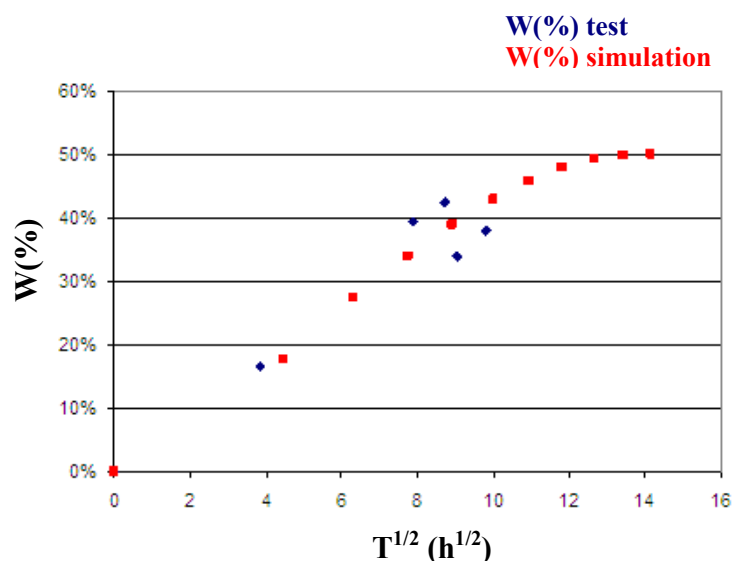

Fig. 15. Mean humidity for IMS sample

In comparison with simulation, these experiments were not long enough to attend the stabilization. Then, it was difficult to make conclusion about the relevance of the model. It is necessary to have more experimental recorded data, especially during the beginning of the test.

\section{CONCLUSION}

This new approach of reliability tests aims at understanding the interactions between environmental factors and their influence on the evolution of electrical and thermo-mechanical parameters. Design of experiments methodology has been chosen to combine environmental stress with electrical one.

The experimental results allow to quantify the influence of the pressure on humidity. The mass variation of test vehicle under depression being negligible, the only phenomenon to take into account is the Fick diffusion. Then simulation models could be validated to study the humidity-pressure interaction on the packaging materials.

Work is under progress to analyze the results from design of experiments and the correlation with multiphysics simulation, for a better understanding of failure mechanisms of IGBT converters in combined aeronautics stress. 


\section{ACKNOWLEDGMENT}

This work was supported by the CEPIA (Convertisseur Electronique de Puissance à Intégration Avancée) program, labeled by AESE (World Competitiveness cluster Midi-Pyrénées and Aquitaine, Aeronautics, Space and Embedded Systems) and funded by DGE (Direction Générale de l'Equipement).

\section{REFERENCES}

[1] T. Lhommeau, X. Perpina, C. Martin, R. Meuret, M. Mermet-Guyennet, and M. Karama, "Thermal fatigue effects on the temperature distribution inside IGBT modules for zone engine aeronautical applications," Microelectronics Reliability 47 (2007) 1779-1783.

[2] U. Scheuermann and U. Hecht, "Power Cycling Lifetime of Advanced Power Modules for Different Temperature Swings," Proc. PCIM Nuremberg 2002, pp. 59-64.

[3] G. Coquery and R. Lallemand, "Failure criteria for long term Accelerated Power Cycling Test linked to electrical turn off SOA on IGBT module. A 4000 hours test on $1200 \mathrm{~A}-3300 \mathrm{~V}$ module with AlSiC base plate," Microelectronics reliability, Vol. 40, issues 8-10, august/october 2000, pp. 1665-1670.

[4] A. Micol, A. Zeanh, T. Lhommeau, S. Azzopardi, E. Woirgard, O. Dalverny and M. Karama, "An investigation into the reliability of power modules considering baseplate solders thermal fatigue in aeronautical applications," Microelectronics Reliability 49 (2009) 1370-1374

[5] N. Patil, D. Das, K. Goebel and M. Pecht, "Identification of Failure Precursor Parameters for Insulated Gate Bipolar Transistors (IGBTs)" 2008 International conference on prognostics and health management.

[6] J C. Whitaker, "Design for reliability," edited by Dana Grow \& Alec Feinberg.

[7] Duclos, Emmanuel, "Introduction aux plans d'expériences", Doussard, Emmanuel Duclos Conseil 2008.

[8] H. S. Kim and H. G Song, "Investigation of moistureinduced failures of stacked-die package," Microelectronics Reliability 47 (2007) 1673-1679.

[9] S. Azzopardi, J.P. Fradin, M. Médina, R. Meuret, M. Piton, P. Rollin, C. Tereskiwiez and P.E. Vidal, "Etude prédictive de la fiabilité de l'électronique de puissance embarquée : projet CEPIA", in proceedings of Electronique de Puissance du Futur, Tours, France (2008).

[10] Oussama ZAKI, «Contribution à l'étude et à la modélisation de l'influence des phénomènes de transfert de masse sur le comportement mécanique de flacons en polypropylène ", $\mathrm{PhD}$ Thesis, Université Paris-Est (2008). 